\title{
SOBRE EL TRATO DE LOS HECHOS HUMANOS COMO OBJETOS
}

\section{Ciencias del hombre y filosofia}

1.1. El proyecto de conocer de modo científico al hombre o, más modestamente, de tratar de manera racional los asuntos humanos, ocupa en la actualidad a tan gran número de personas que, con toda justicia, se siente uno desconcertado ante los escasos resultados obtenidos. Sin embargo, quedan algunas razones para tener esperanza a quien observa con atención los movimientos desordenados de este gran cuerpo infantil. El estado actual de esas "ciencias" puede compararse todavía al de las ciencias de la naturaleza en los tiempos anteriores a Galileo. Aquí, queremos examinar lo que consideramos el obstáculo esencial que detiene, en este dominio, el despliegue de un saber científico; así pues, intentaremos precisar las relaciones del objeto que tal ciencia busca, con la vivencia que constituye el dato indeterminado $\longrightarrow$ más bien sobredeterminado- del que parte.

Con respecto a las ciencias de la naturaleza que acabamos de evocar, conocemos muy bien, grosso modo, las peripecias y los momentos decisivos de la formación de un objeto accesible de conocimiento. En todo caso, sabemos que la vivencia compleja apresada en la experiencia de las cosas sensibles se ha convertido en objeto de una mecánica y de una física, por ejemplo, cuando se la quiere reducir a un modelo ${ }^{1}$ abstracto en el que no figuraron primero más que la espacialidad, el tiempo y la "resistencia" al movimiento. Las dificultades más generales que encuentra tal reducción del mundo comúnmente experimentado como real parecen ser de dos órdenes. En primer lugar, ¿cómo definir y justificar las convenciones de la representación por medio de un modelo? $Y$, desde ese punto de vista, la elección inicial galileo-cartesiana no puede ser considerada en modo alguno como un "paradigma" cualquiera, que sucediera a otros igualmente aceptables; marca una ruptura profunda y duradera, el punto de partida, en ese dominio, de una idea del conocimiento efectivamente conceptualizable y que proporçiona deducciones bien fundadas. En segundo lugar, ¿cómo controlar las proposiciones así deducidas de la estructura del modelo? Sabemos que la respuesta es, en este caso, la previsión y la intervención dirigida, concepciones radicalmente extrañas al antiguo ideal de la ciencia y que proponen también un programa aún válido y que sigue sin competidores.

1 En este texto, "modelo" se tomará siempre en el sentido de esquema abstracto de una entidad relativamente más concreta. Ya hemos explicado en otro lugar la elección de este término (por ejemplo, en "L'explication dans les sciences sociales", Inf. dans les Sc. soc., 10, 2, 1971, P. 33, nota 1 . 
1.2. En el caso de las ciencias del hombre, la transmutación de la vivencia compleja y cambiante que es el hecho humano, aun en los aspectos que por lo común se reconocen como públicos, en objeto científico sigue siendo un problema. No se trata de que para el desarrollo de una ciencia sea requisito una definición previa explícita y general de su objeto. Por el contrario, la física y la biología son más bien explicaciones progresivas por su objeto. Pero no es menos verdadero que entonces cada aspecto objetivado de la experiencia sensible, cada fenómeno se identifique por medio de criterios accesibles a todos los que posean un instrumental material e intelectual determinado: Esos criterios, por refinados, por mediatos, por abstractos que puedan parecer, no "salvan" menos los fenómenos, en ese sentido que autorizan siempre, dentro de los límites de una tolerancia reconocida, el poner en correspondencia unívoca los fenómenos percibidos y, en consecuencia, vividos por una conciencia privada, con su esquematización públicamente inteligible.

Ahora bien, el sociólogo, el psicólogo, el economista no están capacitados, la mayor parte del tiempo, para mostrar tales criterios. ¿Con qué dificultad específica tropiezan, pues, para "salvar" sus fenómenos? Damos el nombre de significaciones a esos aspectos sui generis de nuestra experiencia que caracterizan el hecho humano en cuanto tal. ${ }^{2}$ Desde que el hombre fue percibido - se le supuso - como protagonista, hemos considerado el hecho experimentado como "remitente a" otra cosa, de acuerdo con el modelo de las palabras del lenguaje o de nuestras imágenes mentales. Se trata de una noción primitiva, más allá de la cual resulta vano tratar de remontarse, ya que todo conocimiento formulable por medio de un sistema de signos la supone. El carácter privilegiado de los fenómenos no humanos consiste justo en que pueden ser muy fácilmente percibidos y concebidos como despojados de toda remisión simbólica. La prehistoria de las ciencias de la naturaleza es el relato de esta ascesis conquistada. Sin embargo, no basta decir que el hecho humano es apresado de inmediato como signo. Hay que añadir aún que su aprehensión postula la integración de esa remisión dentro de una totalidad virtual que no se confunde con un sistema de causas y efectos. Así, tal o cual gesto percibido de un ser humano es apresado como posible "expresión" de una "persona", tal o cual institución como posible "expresión" de una "sociedad".

Que no se diga ahora que basta, por consiguiente, con reconocer el carácter confuso y borroso de tales totalidades para que se desvanezca el espectro. Si fuese posible dar una explicación decididamente reductora, que expulsara de modo radical las significaciones del hecho humano, debería satisfacer, pues, las mismas exigencias a las que se someten con éxito las explicaciones de las ciencias de la naturaleza. Pero no conocemos ninguna que no sea o

2 Este concepto se introdujo y precisó en Essai d'une philosophie du style, 1968, cap. $V$, en especial V. 3-11. 
desesperadamente trivial o del todo inaccesible a cualquier ensayo de refutación y, en consecuencia, sin contenido.

Así, pues, nuestra hipótesis epistemológica es que el problema fundamental de las ciencias del hombre es encontrar el medio de otorgar derecho de ciudadanía a las significaciones en un sistema de conceptos abstractos, que conserve las propiedades generales de fecundidad reductiva y de refutabilidad potencial de los modelos del físico.

1.3. Hay que decir desde ahora una palabra acerca del tipo de solución dado por la filosofía al problema del conocimiento del hombre. Ya que tal tipo - cuya desaparición próxima nada nos autoriza a profetizar - debe ser, en nuestra opinión, constantemente reconocido, reverenciado y cultivado, tanto más cuanto mejor se comprenda y ponga en obra el proyecto radicalmente distinto de una ciencia de los hechos humanos. Ahora bien, en Francia, la confusión de los dos proyectos está de moda; ignorancia, neurosis o pilleria, cuando conviene hay que tener la palabra ciencia en la boca. Sin embargo, el filósofo no se propone en modo alguno construir modelos abstractos del comportamiento y de las obras del hombre. Quiere restituir a una organización sistemática y explícita la totalidad a la que remiten las significaciones. Desde luego, no a la manera del artista que reproduce y traslada a un material concreto dado el sistema de significaciones que experimenta. El filósofo trabaja con conceptos y, en cuanto filósofo, no sabría ser un fabricante de simulacros, por asombrosos, por luminosos, por magníficos que su talento literario fuera quizá capaz de provocar. Su tarea es hacer aparecer en traducción conceptual — pero no formal_ las significaciones más o menos confusas apresadas en la experiencia por los hombres de su tiempo y proponer su encadenamiento en una totalidad absoluta. Llamamos a esto "interpretar", empresa que, en opinión nuestra, es infinitamente renovable $y$, en ciertas condiciones de civilización, repetida como las variaciones de una fuga para la cual no habría solución.

Decir en qué consiste la naturaleza conceptual de la interpretación filosófica, cuáles son los modos de encadenamiento que la ligan, he ahí una tarea filosófica de interpretación que no abordaremos aquí. Simplemente queremos insistir en la necesidad de mantener separados, como algo absolutamente distinto, el proyecto filosófico y el del sabio. La cuestión que el primero plantea a propósito del hombre concierne, diríamos, a la significación de su "ser", si no temiéramos introducir con ello las ambigüedades que resultan de un uso de la palabra ser anterior a la puesta en evidencia de un concepto radical de la ciencia. Esta última, comprendida en un sentido de ahora en adelante imposible de recusar, no sería capaz de formular una cuestión global única; digamos que busca construir modelos para los diferentes aspectos del hecho humano, que fragmenta por necesidad. Cómo pueden dejar huellas en esos modelos las significaciones irreductiblemente asociadas 
en la experiencia a tales fenómenos, sin que la ciencia se convierta en una filosofía vergonzante, he ahí el problema cuyo examen esbozaremos aquí.

\section{La reducción a modelos "energéticos"}

2.1. En el estado actual de las ciencias del hombre, la reducción del fenómeno se efectúa de acuerdo con dos estrategias, tomadas a las ciencias de la naturaleza, y conduce a dos tipos de modelos, que hemos nombrado en otra parte "energético" y "cibernético". En el primero, el problema de las significaciones o se ignora o se resuelve muy ilusoriamente por la asimilación directa de éstas a "fuerzas", cuya dinámica o estática es concebida tácitamente a imitación, más o menos burda, de las de los físicos. En el segundo, que superpone al circuito de los flujos "energéticos" un circuito de "información", se supone que las significaciones se reducen naturalmente a este último. Pero es admitir como resuelto el problema de su transcripción formal. Ahora bien, cuando ese problema se aborda de frente, su elaboración lleva, según creemos nosotros, a un tercer tipo de modelo, que hemos llamado "semántico", pero que hoy en día no consideramos tanto como un tipo autónomo de modelo, sino como una especie de subprograma interno en la economía general del establecimiento de modelos con respecto a un hecho humano. Para comprender mejor su naturaleza y función, comenzaremos por subrayar algunos puntos, que nos parecen esenciales, de una epistemología de los programas globales en relación con la construcción de los modelos energético y cibernético.

2.2. La imagen simple de un sistema energético es la de la "caja negra" con una entrada y una salida. Resulta pues demasiado intuitivo llamar "energía". a lo que entra en la caja negra y sale transformado de ellà, pero sólo se retendrán como rasgos distintivos de tal entidad dos caracteres pura. mente formales

1) El "flujo" considerado es homogéneo, lo mismo que el circuito que recorre, homogeneidad cuyo sentido se comprenderá mejor por comparación con los modelos cibernéticos.

2) Es posible agregar a este flujo, de manera esencial, un parámetro que posea cuando menos ciertas propiedades de una magnitud y cuyo efecto de șalida sea función.

Un buen ejemplo de modelo energético no trivial en ciencias humanas es el proporcionado por la teoría walrasiana del equilibrio del intercambio. Las ecuaciones de demanda de un bien en otro $-D_{i j}=f\left(p_{i j} \ldots p_{k j}\right)$ - junto con las ecuaciones de conservación que Walras llama de "intercambio" $-D_{i j}$. $p_{i j}=D_{i,}{ }^{3}$ fijan las relaciones de equilibrio de los precios y las cantidades

3 Se sabe, por lo demás, que Walras concibió la idea de su modelo económico del equilibrio al leer los Elements de Statique del mecánico Poinsot (1803). 
intercambiadas. Así, pues, puede considerarse como flujo de entrada las cantidades de bienes en demanda y como flujo de salida los precios que se establecen, teniendo ambos el carácter de magnitudes vectoriales en espacios convenientes.

Otro ejemplo más complejo es la teoría durkheimiana del suicidio.

Se ve, por la diversidad de esos dos casos, que consideramos aquí un tipo muy general de modelo explicativo, sin prejuzgar el carácter estático o dinámico del sistema. Pero aun a este nivel de generalidad, se presentan cuestiones y observaciones preliminares.

2.3. En los fenómenos físicos para los que fue inventado en primera instancia, el concepto subyacente al establecimiento del modelo energético es el de estado de un sistema. No nos ocuparemos aquí de la manera en que ese concepto se ha definido y diversificado, no sin trabajos, en el dominio de las ciencias de la naturaleza. Pero conviene advertir, en cuanto al fenómeno humano, que la cuestión o bien ha quedado en silencio o se la ha resuelto muy imperfectamente. Sin embargo, para dar un alcance preciso y controlable a un modelo energético, es necesario dar al fenómeno tratado un marco de referencia, que desempeñe el papel que corresponde al espacio de fases del físico y que permita descubrir los diferentes estados atribuibles al sistema cuyo modelo será el esquema. Dicho de otra manera, hay que distinguir las variables de estado, consideradas como determinaciones suficientes del fenómeno reducido. Ahora bien, esa elección de las variables de estado con respecto a los fenómenos que estudia el sociólogo, el economista, el psicólogo, parece depender en forma muy estrecha de la aprehensión de los fenómenos como significaciones $\mathrm{y}$, en consecuencia, liga de modo clandestino los procesos de objetivación con la aprehensión del mundo humano como totalidad no conceptualizada e incontrolable. Es una aprehensión de este tipo la que orienta el corte del fenómeno mismo y, a fortiori, la disociación de variables. Así, pues, todo sucede poco más o menos como si, para estudiar el arcoiris, el físico eligiera los indicadores del fenómeno en función del poder evocador que para él puede tener cada uno de los colores. Comparación coja e injusta, es verdad, porque en el caso del sociólogo el papel de las significaciones es del todo irrecusable, esencial a este aspecto de la realidad del fenómeno que el modelo querría preservar. De manera que el buen uso de los modelos energéticos no queda aquí garantizado en modo alguno por el rechazo puro y simple de cualquier aprehensión de las significaciones. Sin embargo, hay que exigir, cuando menos, que la determinación elegida como espacio de fases sea significativa, sea reconocida como tal y no tácitamente propuesta como única objetivación neutra o natural.

A falta de ello, surgieron, como sucedió, las querellas sobre el fundamento de la concepción misma de modelo. Ilustremos brevemente esta situación mediante un único ejemplo tomado de la economía. En un artículo 
reciente intitulado "La no pertinencia (irrelevance) de la economía del equilibrio",4 Kaldor acusa a los economistas postwalrasianos de "carecer de la comprensión fundamental del funcionamiento de la economía real" (p. 1240). En su opinión, la ciencia económiça se descarrió a partir del momento "en que la teoría del valor se apoderó de la escena, es decir, desde que la atención se dirigió a las funciones asignativas del mercado, con exclusión de sus funciones creadoras, en cuanto instrumento de transmisión de impulsos hacia los cambios económicos". Es muy evidente que esta crítica -cuyo contenido técnico, muy interesante por lo demás, no debe ocuparnos aquíconsiste en oponer dos determinaciones del estado de un sistema llamado económico, subordinadas respectivamente a dos aprehensiones significativas diferentemente acentuadas y cuyos prototipos podrían describirse con facilidad en Walras o Pareto por una parte, y por la otra en Marx y Keynes.

Tales conflictos, que no podrían ser evitados más que por una relativización explícita de los modelos, muestran los límites de la reducción energética. Sin embargo, no habría que concluir de ellos la vanidad de la empresa; simple y sencillamente, la atención del filósofo, una de cuyas tareas es seguramente ésta, debe ser avivada de modo constante por las dificultades y anomalías que entraña de manera ineluctable la transposición de los cenceptos esencialmente vagos de nuestra aprehensión de los hechos significativos en los conceptos exactos que requiere la ciencia. Y quizá sería necesario decir que el criterio epistemológico profundo del hecho no humano es que la reducción de los conceptos vagos -ilustrados en ese dominio por las aporías clásicas del tipo Sorites- puede hacerse sin dificultades dirimentes y conduce a sistemas coherentes de abstracciones. En otras palabras, el carácter vago de las nociones directamente sacadas de la experiencia no aparece aquí como algo esencial.

2.4. Esta observación nos lleva a comentar, relacionándolas, diversas oposiciones entre niveles de abstracción del fenómeno, que conciernen en mayor o menor medida a las condiciones de posibilidad y a las limitaciones del modelo energético.

La distinción fundamental puede tomarse de Descartes, aunque también podría sacarse de Locke, en la medida en que aquí hacemos abstracciones de la interpretación metafísica. En el análisis del pedazo de cera, aparece a través de las transformaciones de un objeto sensible, una invariable, que Descartes remite a un sustrato absoluto, la extensión, que el entendimiento apresa. Sus determinaciones son recibidas como causas de las propiedades sensibles, las que se relacionan primero con la unión del alma y del cuerpo, y son así los signos de quid ad illam externa corpora prodesse possint aut: nocere (Principia, II, ed. A \& T, tomo VIII, p. 41). Así, pues, para la física 
cartesiana el problema es explicar esas cualidades sensibles a partir de las solas propiedades directamente inteligibles del sustrato extenso.

Tal desnivelación epistemológica, que opera aquí en el dominio de las cosas materiales, se refleja de manera diversa en ciertas concepciones del hecho humano y de su conocimiento posible. Resulta instructivo comparar entre sí algunas de esas oposiciones antiguas o recientes: infraestructurassuperestructuras, latente-manifiesto, estructuras profundas-estructuras de superficie, cuyos respectivos autores conocemos. En cada una de esas parejas aparece, en diverso grado, la asociación de un significante y de aquello a lo que remite, considerado como determinante, profundo, oculto. Cierta estrategia del conocimiento del hecho humano es común a todas ellas y consiste en buscar, más allá de una organización más o menos inmediata de las significaciones que constituyen el dato vivido, una organización de otro orden, que da cuenta de la primera.

Por lo que se refiere a la oposición infraestructura-superestructura, tomada en su sentido marxista primitivo, la organización oculta determinante correspondería a un tipo energético de modelo: el de las formas de producción. Pero muy pronto se da uno cuenta de que al ponerlo en obra recurre a nociones ambiguas, como la de valor y de clase social. De manera que el mérito que hay que atribuir a Marx no es el haber liberado de significaciones la visión del hecho humano para descubrirle un fundamento "material", sino más bien, por el contrario, haber mostrado mediante el ejemplo cómo una reducción energética sigue siendo tributaria de las significaciones mismas. Sin embargo, en Marx queda el problema de dar un contenido satisfactorio y operatorio a la distinción entre una infraestructura y una superestructura, la interpretación de la primera en términos estrictamente energéticos ${ }^{5}$ parecería destinada al fracaso.

A pesar de las apariencias, la oposición freudiana entre latente y manifiesto corresponde a un movimiento comparable, cuyo esquema epistemológico resumimos, sin tomar en cuenta aqué las vacilaciones y la evolución de su autor:

1) El comportamiento humano es esencialmente portador de significaciones, ocultas, cuando menos en parte, para el actor.

2) La tarea mayor del analista, en cuanto psicólogo "de profundidades", es restituir lá organización interna de las significaciones en un individuo.

3) Esta organización puede ser esquematizada como sistema de fuerzas.

- Se trata de la interpretación que propusimos en Pensée formelle et sciences de l'homme, 1960, § 6.8. En Essai d'une philosophie du style, 1968, § V. 11, modificamos nuestro punto de vista, reservando el nombre de superestructuras para los "residuos" de significación que los modelos no pueden conformar.

Aquí mantenemos esta última interpretación, aunque adaptándola a una concepción más precisa de los sistemas significantes. Correspondería a la redundancia irreductible de tales sistemas cuando se los reduce a sus modelos semánticos formales. Vemos que cae más allá de la ciencia, y sólo puede depender de la interpretación filosófica. 
Es aquí muy notable que las significaciones se encuentren finalmente reducidas a elementos energéticos y aun al sentido más mecánico del término. La parte emergente, por así decirlo, del comportamiento humano, se concibe como un sistema simbólico. cuya esquematización no podrá hacerse pues por medio de modelos energéticos; por el contrario, la parte sumergida, y dominante, se reducirá a un juego de fuerzas cuya descripción adecuada será proporcionada por un modelo energético. Las dificultades que se oponen a poner en marcha esta concepción como teoría y práctica científica provienen pues del paso directo dado por Freud de un sistema de significaciones a un sistema de fuerzas, así como uno de los problemas del marxismo es el paso inverso de un sistema de fuerzas a un sistema de significaciones. En el psicoanálisis, considerado como técnica de intervención terapéutica, el paso se da en efecto por medio de procesos y rituales que no tenemos por qué examinar. Pues se trata entonces de un arte que, tanto o más que el de la guerra, parece ser todo de ejecución. Pero en el plano del conocimiento, y si el psicoanálisis es también un método para establecer y controlar los modelos, ningún procedimiento regulado ha llegado sin embargo hasta ahora a garantizar dicho paso y, por el contrario, vemos multiplicarse las Iglesias, los Grandes Sacerdotes y los fieles.

La tercera oposición, de origen lingüístico, ${ }^{8}$ es la de estructuras de súperficie y estructuras profundas. Parece corresponder, cuando menos en Chomsky, a la transposición del trascendental kantiano en una teoría del lenguaje. Hay formas a priori -y en consecuencia universales- en la expresión, o más exactamente aún de competencia de la lingüística, así como en Kant existen formas a priori de la intuición y principios a priori de la aprehensión de los objetos. Toda secuencia de signos bien formada $\longrightarrow$ lo bastante bien formada - en una lengua, sería así derivable de una o más fórmulas fundamentales, cuya constitución se conforma a un modelo engendrado por las reglas de una "gramática profunda", común a todas las lenguas y al poder de todo espíritu humano. Es de notarse que la empresa lógica de Aristóteles sólo postula la reductibilidad de las expresiones declarativas a una fórmula única. La teoría en cuestión extiende esta hipótesis a toda clase de enunciados. Así, pues, el resultado de un análisis dirigido por esta conjetura debería presentarse como un modelo abstracto universal de toda lengua; ¿de qué naturaleza sería ese modelo? Si hiciera aparecer relaciones últimas entre elementos que prueban ser irreductibles a aquellos con los que puede contentarse el lógico o, en un sentido más amplio, el matemático, se habría constituido pues una gramática general de la expresión natural, por oposición a una lógica general o, si se quiere, a una gramá-

6 Como se sabe, fue Chomsky quien la bautizo, al reflexionar sobre las reglas gramaticales usuales. Existe también, en esos mismos términos, aunque con un sentido muy difèrente, en Wittgenstein (Philosophical Investigations, II. 664). 
tica general de los sistemas formales. ${ }^{7}$ De no ser así, la gramática profunda se identificaría en última instancia con esta última. ${ }^{8}$ En cualquier caso, todas las propiedades específicas de las lenguas naturales, que las hacen inasimilables a los sistemas formales, deberían ser introducidas por las solas reglas de transformación que hacen pasar los esquemas profundos a las expresiones terminales concretas. Pero en el estado actual de la lingüística transformacional, está permitido preguntarse si el establecimiento laborioso e indefinidamente refinado de esas "reglas" no es a fin de cuentas un artificio arbitrario para reintroducir lo que había sido arbitrariamente evacuado.

Así, pues, lo que nos parecería justificar la empresa sería más bien la eventualidad de encontrar un modelo profundo irreductible a la lógica. Pero conviene señalar ahora que tales modelos, aunque abstractos en relación con el lenguaje real, al no ser puramente lógicos, tendrían un cierto contenido: las relaciones primitivas y las clases de símbolos originarios remitirían así con fuerza a una experiencia ya diferenciada. $Y$ los modelos lingüísticos profundos, por no ser simples esquemas vacíos, simples marcos de información, serían por tanto los prototipos más simples, pero también más completos de lo que llamamos sistemas significantes. Así, lá lingüística se encontraría sumergida en una fisio-psico-sociología fundamental del conocimiento, cuyo problema preliminar es justo el del paso de las significaciones vividas a los símbolos.

\section{La reducción cibernética}

3.1. Antes de considerar el problema al cual nos hemos visto àsi llevados de nuevo, es necesario examinar la segunda estrategia de construcción de modelos anunciada en $\$ 2.1$. Llamamos modelo cibernético a toda esquematización abstracta de ciertos fenómenos que superpone un circuito, llamado de información, al diagrama energético antes definido. Dentro de tal esquema, cuyo bien conocido prototipo es el del anillo de regulación, hay un "flujo de energia" secundario, y sin importancia con respecto al principal, que va del efecto de salida de ese último hacia la entrada. Pero funcionalmente no habría que considerarlo como una simple rama de ese flujo, aunque pudiera ser una derivación efectiva de él; le es heterogéneo en cuanto que el efecto de salida resultante no es función de su parámetro de magnitud.

7 Es ésta la hipótesis directora de Hjelmslev desde 1928: da a este sistema fundamental universal no lógico el nombre de "el estado abstracto" del lengúaje. (Cf. Principes du grammaire géneral, en especial, cap. IV, pp. 257-267.) vincentes.

Es verdad que las "cinco categorías funcionales" que propone están lejos de ser con-

8 Es la tesis de Wittgenstein en el Tractatus. 
Su acción se ejerce por medio de un transductor de "palpación" a la salida principal, y un tranductor de mando a la entrada. En cuanto flujo de energía desempeña el papel de simple soporte para lo que se ha convenido en llamar información.

Considerada en su funcionamiento global, tal máquina, si es lo bastante compleja, es susceptible de imitar no sólo los fenómenos de regulación simple, por "piloteamiento" del flujo de energía, sino aun de los fenómenos de adaptación y de homeostasis. Es decir, que ciertos rasgos estructurales de la máquina misma han sido modificados, pues, por su propio funcionamiento. Se ve por consiguiente que la introducción de un circuito de información vuelve a inscribir en un mismo esquema dos niveles de organización, uno de los cuales puede designarse como meta estructura, en la medida en que produce en cierta forma una imagen del otro, que sirve de guía para modificarlo. De alli resulta el privilegio epistemológico de tales modelos con respecto a los fenómenos biológicos y humanos. Lo que queremos examinar aquí es, pues, ese rasgo de la organización cibernética, dejando de lado cualquier otro problema de método o de técnica.

3.2. Decir que un modelo cibernético es informativo equivale a decir que comporta una imagen del mundo exterior y eventualmente de sí mismo. La palabra imagen es evidentemente metafórica aquí y debe ser tomada en el sentido abstracto de los matemáticos. Supone un morfismo del conjunto de los datos en un conjunto de elementos llamados signos. El dato, en el caso que nos interesa, es lo que hemos llamado la experiencia o lo vivido. El conjunto de signos es realizable de diferentes maneras, pero resulta evidente que tiene que tener una estructura propia compatible - en el sentido de los matemáticos - con la organización "natural" del dato, es decir que sea posible hacer corresponder sin contradicción signos y relaciones abstractas entre signos con los elementos y eventualmente con las relaciones concretas vividas. Esta ley de correspondencia y las relaciones entre signos definen con respecto a cada uno de éstos lo que llamamos, en sentido estricto, su sentido. Desde ese punto de vista, todo esquema de información es con seguridad convencional, pero la libertad de la convención está efectivamente limitada por las condiciones de utilización del morfisma. Por otra parte, si hablamos de morfisma en general y no de isomorfismo es porque la multiplicidad de los elementos de lo vivido está con mucha frecuencia reducida por una relación de equivalencia que anula aquellas de las diferencias que la imagen no distinguirá.

Ya se habrá notado que utilizamos a propósito de lo vivido las palabras "elemento", "relación", "morfismo" que sólo tienen una definición estricta en un sistema de objetos abstractos. Pero la legitimidad de tal uso descansa justo en la posibilidad de una reducción informativa, que nos haga aceptar la sustitución del corte vago de lo vivido por el corte riguroso del sistema de signos. 
En un modelo cibernético de fenómenos físicos, los signos puestos en circulación por el circuito informativo constituyen siempre una reducción del dato, del que no son nunca otra cosa más que copias por completo infieles; ya que aun en el caso de una información "analógica", hacen evidente una forma extraída del dato. En el caso no analógico, esta abstracción se lleva hasta la construcción de un sistema formal, noción de la que ya hemos propuesto la caracterización en otro lugar. ${ }^{\circ}$ Presentar un modelo cibernético como explicación de fenómenos humanos es comprometerse a entregar, además del programa de conjunto de funcionamiento del modelo, articulado de acuerdo con su doble circuito, una especie de subprograma que formule el código de lo vivido en un sistema formal. Ahora bien, esta transcripción no se efectúa a partir de un dato que pudiéramos llamar inerte: lo vivido es ya aquí, muy evidentemente, él mismo un sistema simbólico y cargado de significaciones. Así, pues, nos parece que la reducción cibernética, a fin de respetar el carácter específico del hecho humano, debe comportar de modo necesario una etapa intermediaria que consiste en una primera descripción conceptualizante que desemboque en lo que hemos llamado un modelo "semántico". A esta descripción la llamamos hace poco "semiología II", en un ensayo de sistematización del tratamiento general de los signos. ${ }^{10}$ Ahora nos parece mejor apresar su lugar que es, como hemos visto, el de una etapa intermediaria y de una instancia auxiliar en la elaboración de los modelos de funcionamiento del hecho humano. Hasta nos veremos llevados a concluir que el único carácter propio del modelo semántico es no poder ser establecido más que por extracción de una pluralidad de sistemas formales. El hecho de que esta pluralidad sea esencial nos parece sin embargo suficiente para justificar que se la ponga aparte. También, las empresas propiamente estructuralistas en antropología y en sociología - cuyo prototipo lo proporcionan las de C. Lévi-Strauss_ deben situarse, dentro de esta perspectiva, no como fragmentos de conocimiento acabado, sino como el logro de subprogramas, esenciales para la constitución de las ciencias, que explicarían por modelos cibernéticos completos, lo que tiene lugar en el tiempo, el espacio y las individualidades realmente apresables por la experiencia. Pero jay! aún estamos muy lejos de este ideal. Aquellos que, menospreciando tales tentativas, pretenden por el contrario poder exponer de un golpe los secretos del mundo humano y de su historia son, no

9 Cf. "Langue et systemes formels", en Language, 21, 1971, pp. 71-87. Se pueden resumir así: 1) Disociación estricta de los caracteres pertinentes en la materia del signo $y$, en consecuencia, discontinuidad absoluta de los elementos significantes. 2) Enumeración efectiva de esos elementos significantes. 3) Leyes unívocas de concatenación en expresiones bien formadas.

10 Cf. Essai d'une philosophie du style, cap. V. Las consideraciones desarrolladas en el presente articulo fueron provocadas con frecuencia por las preguntas y criticas que a este propósito ha tenido a bien comunicarnos nuestro colega J. Molino. 
obstante, muy impertinentes o bien poco conscientes. Pero nosotros no seguiremos más a quienes ven en esos ensayos estructurales el paradigma de una ciencia acabada del hombre.

3.3. Ahora bien, los problemas epistemológicos que se plantean desde luego a ese nivel pueden agruparse en dos apartados:

1) ¿Cómo definir el alfabeto —o los alfabetos - del sistema informativo en un modelo cibernético humano, es decir, cómo recortar, en el tejido cerrado de las significaciones, unidades de sentido?

2) ¿Cómo describir de manera aceptable la "gramática" de la información que opera en el modelo?

En otras palabras, ¿cómo pasar de algo vivido, esencialmente cargado de significaciones, a un sistema relacional de signos provistos de sentido?

Un buen ejemplo de reducción drástica de las significaciones lo proporcionaría la economía marginalista que, partiendo del fenómeno humano del intercambio, le anula todos los componentes significantes, con excepción de la búsqueda de una satisfacción máxima, y transcribe esta búsqueda misma en los términos más abstractos que sea posible, eliminando por ejemplo el tiempo, la discontinuidad de los bienes de consumo, la existencia de umbrales, de tabúes y de costumbres. A ese precio, el sentido de un hecho económico es asignable como conjunto de relaciones abstractas, expresables por medio de los conceptos del análisis matemático y eventualmente asociables a números. Resultaría vano minimizar aquí el hecho de que un proceso análogo ha conocido y sigue conociendo los mayores éxitos en las ciencias de la naturaleza. $Y$ con certeza, deseamos ser de aquellos que prefieren ver a la ciencia asumir, de modo provisional, los inconvenientes de una empresa de ese tipo, más que verla precipitarse hacia una interpretación global magnífica, incontrolable y vana del conjunto significante que cree poder abarcar. La virgen prudente es estéril, se dirá; ¿lo será la virgen loca? ¿Podemos esperar que sea la primera para la que se preparan fecundos esponsales?

Se observará que, en el ejemplo elegido, la reducción del homo oeconomi. cus sólo se ha hecho, en primer lugar, con vistas a construir un modelo puramente energético, el de Walras y Pareto, pero que de inmediato surgieron tentativas para constituir modelos cibernéticos, donde una información económica, codificada según el filtro del homo oeconomicus, enriquecido eventualmente con componentes temporales, se superpone al juego de "fuerzas" económicas. Por lo demás, nuevos aspectos significantes del fenómeno son transcritos en los sistemas más recientes, sea bajo la forma de factores energéticos extraídos de la experiencia del comportamiento social en general, sea, más tímidamente, bajo la forma de nuevos elementos informativos: ideologías, aspiraciones, saberes. Enriquecimiento que Pareto, cuando menos, entre los grandes fundadores, había entrevisto ya, y que Marx quiso introducir de modo tan brutal en el esquema energético antiguo de la economía clásica, 
que el aparato abstracto del modelo casi desapareció del todo en provecho de una filosofía de la historia.

La lección es ejemplar. Las ciencias del hombre se encuentran, por su propia naturaleza, colocadas ante un dilema. $O$ reducir totalmente las significaciones a sentidos estrictamente conformados, a riesgo de ver desaparecer la especificidad de su objeto y degenerar en ejercicios lógico matemáticos. $O$ introducir en forma masiva e ingenua las significaciones como tales y, perdiendo toda posibilidad de construir verdaderamente modelos abstractos, mudarse, en el mejor de los casos, en hermenéutica filosófica, en vaticinios míticos en el peor.

\section{${ }_{\text {¿Pueden objetivarse las significaciones? }}$}

4.1. Es concebible que en estas materias la tarea del filósofo sea odiosa. Al esforzarse por definir la significación de la ciencia - y no por hacer una ciencia de la ciencia - no aporta ningún elemento de solución. Se limita a señalar, reconocer, valorar los obstáculos, apreciar los logros, gritar algunas veces que el rey va desnudo. Aquí, tratamos, sin embargo, de mostrar la necesidad en que se encuentran las ciencias del hombre de reflejar de cierta manera las significaciones esenciales de la realidad vivida que se proponen explicar. Trataremos también de precisar en la medida de lo posible las dificultades con que tropieza esta empresa y de formular su programa. Empecemos por denunciar brevemente el espejismo del paradigma lingüístico.

Sabemos qué interés ha despertado, con todo derecho, entre algunos de los mejores artistas y artesanos de las ciencias humanas, el desarrollo de una lingüística estructural. De allí a considerar la lengua como objeto por excelencia de las ciencias del hombre y a querer reducir a los procedimientos lingüísticos cualquier método para el estudio del hecho humano sólo hay un paso. Nuestro propósito es, por el contrario, subrayar la especificidad muy fundamental de la lengua, y los límites que encuentra, por consiguiente, la extensión de los métodos del lingüista. No podemos exponer aquí una concepción detallada de la lengua y de los sistemas simbólicos que hemos desarrollado en otra parte. ${ }^{11}$ Limitémonos a recordar aquí lo esencial para nuestro presente propósito.

Una lengua natural es un sistema simbólico que comprende una articulación soporte, que es un sistema formal. Es el que describen los fonólogos y cuyo carácter distintivo es, en opinión nuestra, no tanto el estar compuesto de signos desprovistos de remisiones a la experiencia - desprovistos, si se quiere, más precisamente, de denotación-, cuanto tener las propiedades muy particulares de los sistemas formales.

A esta articulación sustrato se superponen, por reagrupamiento y por

11 Cf. por ejemplo el artículo ya citado, "Langue et systemes formels", § 4.1-4.3. 
modulación de ciertos aspectos de sus unidades, otras articulaciones jerarquizadas, cuyos nuevos elementos o nuevas señales remiten entonces a diferentes niveles de experiencia.

Entre los sistemas de signos que constituyen esas articulaciones, sólo el de la articulación soporte está delimitado y determinado sin equívocos por quien usa la lengua, el significante propio de cada elemento, es decir, el conjunto de los aspectos de su materia necesarios y suficientes para distinguirlo de los otros signos. No sucede lo mismo con los otros niveles de articulación y la frontera de lo no-pertinente y lo pertinente puede seguir siendo muy vaga.

4.2. Así, si se caracteriza una lengua natural como sistema simbólico particular, conviene, en opinión nuestra, insistir en tres consecuencias.

1) El concepto de lengua no podría plantearse como el de un individuo completo y autónomo, sino más bien como el de una faceta de un hecho humano más complejo. La proclamación saussuriana de independencia es de modo muy evidente un artificio polémico y metodológico; perfectamente justificado en su tiempo y en su contexto y que, si bien conserva sin duda hasta ahora toda su fuerza, no puede ser tomado al pie de la letra más que como efecto de una ceguera.

2) La lengua interfiere constantemente con los otros sistemas simbólicos que constituyen otras facetas del hecho humano, en particular en la medida en que sirve a todos como metalenguaje universal. En la realidad social, lo mismo que en el fuero interno, vemos constantemente transpuestos, mencionados y descritos los otros sistemas de símbolos. A tal grado que, con frecuencia, es imposible reconstituir tales sistemas sin importar a ellos los rasgos pertenecientes a la lengua de las sociedades cuyo producto son. En este sentido, sobre todo, podrá comprenderse y reducirse a su justa proporción la idea metafísica de Humboldt acerca de que toda visión del mundo y toda cultura es hechura de la lengua.

3) Todavía hay otra manera en que la lengua se enlaza con otros sistemas simbólicos, en cuanto que con mucha frecuencia les proporciona su sustancia. Dicho de otra manera, los elementos significativos más o menos bien definidos de tales sistemas - como los de los mitos, por ejemplo-, son ellos mismos fragmentos de mensajes lingüisticos ya provistos, por consiguiente, en cuanto tales, de remisiones a la experiencia. De modo que la organización de la lengua interfiere de manera compleja y muy indefinida con la del sistema simbólico que le está sobreimpuesto. Un ejemplo muy sencillo y excepcionalmente claro y distinto de esta intricación lo proporciona la lógica, sistema formal construido con elementos que son, en sí mismos, mensajes lingüísticos; pero en ese caso, la regla del juego es justo neutralizar todos los caracteres naturales de esos mensajes y hacer aparecer sus combinaciones como reducidas a un pequeño número de propiedades sometidas a criterios 
unívocos. Así, Aristóteles y los estoicos dividieron la empresa de superponer a la lengua un esquema formal, interpretado entonces, es verdad, como reflejo y modelo de una ontología.

En esas condiciones, se comprende la fuerza de atracción ejercida por la lingüística, y la sureptio mal consciente por la que se identifica indebidamente con las estructuras de la lengua toda estructuración de una realidad simbólica.

4.3. Ahora bien, existen otros sistemas simbólicos esencialmente distintos de las lenguas, y son ellos justo los que, al mismo tiempo que el resto de éstas pero de manera independiente, nos parecen proporcionar la materia para esta elaboración "semántica" ya antes anunciada, por la que los artesanos de las ciencias del hombre harán asimilable a su ciencia lo vivido de las significaciones.

Tales sistemas constituyen de modo evidente ya cortes en el dato directamente accesible al observador-participante del comportamiento humano. Si bien su aprehensión misma plantea el problema de la relatividad de la teoría en relación con una práctica, aquí sólo nos ocuparemos de sacar a luz los rasgos característicos y las condiciones de su establecimiento como objeto. Ya se trate de los aspectos de la moda en el vestir en un momento y en un lugar dados, de opiniones políticas, de prácticas jurídicas o de los comportamientos del consumidor, vemos que una parte importante de la "sustancia" de esos sistemas de símbolos es ya en sí misma significante, es decir, que está asociada de manera más o menos difusa a vivencias complejas tota, lizadoras, que pueden pertenecer a un orden por completo diferente, en apariencia, de aquel cuya forma se quiere distinguir.

Por otra parte, la pertinencia de los elementos resulta, muy frecuentemente, vaga. No sólo autoriza su diferenciación mutua los encabalgamientos, sino que aun las remisiones mayores que los caracterizan con todo como elementos provistos de sentido, están rodeadas de un halo de remisiones con. notativas. Damos aquí a esta palabra una doble acepción. La primera es la que Hjelmslev adoptó en sus Prolegómenos: por ejemplo, el connotador francés "se expresa por los esquemas en uso lingüístico que llamamos la lengua francesa". Aquí la connotación es un contenido, pero un contenido metalingüistico; porque se apega a la lengua misma tomada como código, como organización de signos. Así, podría decirse, tomando otro ejemplo, que aquellos de los contenidos fonéticos que, no siendo necesarios para el reconocimiento de los fonemas de una lengua y, por consiguiente, no siendo pertinentes en sentido estricto, denuncian sin embargo el acento extranjero de quien habla, constituyen la expresión de ese connotador. Pero en segundo lugar, reconocemos también como connotación en sentido amplio el conjunto de remisiones más o menos inorgánicas producidas por los contenidos o las formas de la sustancia de un signo, no pertinentes dentro del sistema princi- 
pal al que pertenecen. Es la organización y codificación de esta connotación realizadas a parte post en la producción misma del mensaje la que en otra parte hemos descrito como actividad estilística. Ahora bien, si por lo general en una lengua la frontera está bien delimitada entre el halo estilísticamente explotable y lo que hemos llamado el sentido de los mensajes, no sucede así en los sistemas simbólicos significantes de que aquí se trata, donde los mensajes en el límite, pueden no tener un sentido que les sea propio. El hablar, a propósito de ellos, de un código es por consiguiente abusivo con mucha frecuencia, si esta palabra designa, como es usual, las reglas constitutivas del sentido a parte ante.

De todo esto resulta que, con respecto a tales sistemas, la sintaxis y la semántica —en el sentido ordinario de las palabras - sean casi completamente inseparables. Sin duda alguna, está muy cerca de ser así con respecto a las lenguas naturales. Sin embargo, se podría, simplificando un poco, distinguir tres grados de independencia sintáctica, muy característicos de diferentes tipos de simbolismo. En las matemáticas, y en todo sistema formal, la sintaxis es dominante y autónoma; por así decirlo, absorbe a la semántica que se reduce, entonces, a la vacuidad de un puro esquema de remisión posible hacia contenidos de experiencia. En las lenguas naturales, la separación entre una semántica y una sintaxis es funcional y está bastante bien determinada, aun cuando un análisis pudiera mostrar su relatividad. Pero en los otros sistemas significantes, semántica y sintaxis aparecen de inmediato como indisolublemente asociadas.

De ahí resulta aun que, si es posible la reducción de un sistema significante, no podría conducir a un sistema formal único. La polisemia que caracteriza los sistemas significantes no es una polisemia puntual; se interesa por el conjunto del sistema, que significa en diversos planos. Los exegetas de los textos sagrados conocen desde hace mucho tiempo este tipo de polisemia. Necesitamos aplicarla a los sistemas significantes en general, de manera que la empresa de reducción acabe por superponer y entrecruzar los sistemas formales. Así, se concilian quizá exigencias contradictorias: ya que, por una parte, sólo es, en nuestra opinión, de conocimiento científico -es decir, públicamente controlable y aplicable _ por reducción a lo formal, frontera de nuestro entendimiento; y por otra parte, todo sistema formal es desbordado con certeza por el hecho humano vivido. Así se establece también, en este terreno, el carácter progresivo, histórico e indefinidamente provisional reconocido a las otras partes de la ciencia. Hasta cierto punto, la metáfora de representación de un sólido por diversas proyecciones planas parece aquí esclarecedora: un sistema formal jamás puede ser, con respecto a un sistema significante, más que un geometral entre otros. Pero aquí hay que añadir que la determinación completa de lo proyectado no es realizable por medio de un número finito de proyecciones, como si el "espacio" en 
el que existe tuviera un número infinito de "dimensiones". Es lo que se expresa intuitivamente bastante bien al calificar aquí a lo vivido como sobredeterminado.

En estas condiciones, ¿cuáles serían las tareas primordiales de una semiología orientada hacia la descripción de tales sistemas, tomados como momentos intermediarios entre la experiencia pura y simple de las significaciones y la reducción al modelo cibernético?

4.4. Nos parece que se las puede designar así:

1) Establecer, efectuando, por así decirlo, cortes en la vivencia considerada, diversos trazos formales, es decir, imágenes que tienen las propiedades de sistemas informativos perfectos.

2) Separar, por lo demás, las connotaciones de tipo metalingüístico que se agregan eventualmente a sus signos. Este análisis que no podría intentar constituir por sí mismo sistemas formales, nos parece indispensable en cuanto permite concebir el sistema significante en su uso y preparar su inserción en un modelo de funcionamiento. Resulta bastante claro que este aspecto del análisis señala métodos muy diferentes a los que convienen al primero, y que supone una investigación pragmática en el sentido de Morris y Carnap de los sistemas significantes. Sin duda es necesario que tal exploración se haga independientemente de la esquematización formal antes indicada; pero no habría que olvidar además que esta esquematización formal, separada del comentario pragmático, permanece ciega y, la mayor parte del tiempo, vana. Así, la sistematización formal, o casi formal, de los mitos no basta para proporcionar al conocimiento científico una realidad humana, si no se combina con una teoría empírica de sus connotaciones. Admiraremos, pues, a C. LéviStrauss por haber concebido y emprendido su análisis saussuriano, pero aun suponiendo que se lo hubiese llevado irreprochablemente a cabo, cortado con deliberación de cualquier comentario pragmático, nos parece esencialmente incompleto y no puede justificar las conclusiones metafísicas, por así decirlo, que de él saca su autor.

3) Reconstruir las estructuraciones fugaces y a parte post que, en su uso histórico efectivo, sufrieron los elementos connotativos en sentido amplio - dicho de otro modo, esbozar una "estilística" del sistema significante que aclare algunos aspectos de la inserción en la vivencia de sistemas formales establecidos por análisis. Estos no desempeñan evidentemente el mismo papel que el sistema formal inmanente que sirve de estructura portadora a un lenguaje; este último, aun si su formalización está sujeta a variantes, aun si tiene "varias soluciones", como ha mostrado Yuen-Jen Chao, a un problema fonológico dado, es sin embargo único, en cuanto solo sustrato esencialmente formal necesario para el funcionamiento de la lengua. Por el contrario, en los otros sistemas significantes, los sistemas formales que el análisis separa son por naturaleza múltiples y concomitantes; desde ese punto de vista, su carác- 
ter de artefactos del conocimiento está mucho más marcado que el de un sistema fonológico. Sin embargo, si el valor de la práctica científica que se expresa por su elección no debe ser tenido por totalmente arbitrario, lo que puede testimoniarlo principalmente es la explicación estilística fina de sus residuos.

Sería ilusorio pretender enunciar las reglas técnicas de esta semiología, que apenas puede comprobarse en el trato concreto de los fenómenos. Cuando más es posible subrayar y comentar los obstáculos mayores a que debe enfrentarse. La dificultad más evidente proviene con seguridad del corte del dato significante en unidades saussurianas. Cuando uno se propone analizar sistemas bastante complejos, la lengua interviene como ingrediente inseparable. Es necesario entonces superar los equívocos engendrados por esta presencia muy impregnante en la sustancia del sistema y tratar de restituirla en su confusa integridad. Se concibe, pues, que, en rigor, un conocimiento científico y práctico del lenguaje amalgamado sea indispensable para quien quiere emprender la segmentación de tal sistema significante. Esta condición se cumple muy rara vez. Sin embargo, no es irrazonable suponer que, si las relaciones de parentesco o los relatos míticos tienen en cuanto tales una estructura propia, sus modos autóctonos de expresión lingüística pueden en ocasiones determinarla, reforzarla o enmascararla. Pero el etnólogo parece estar seguro de que, de ser traducidas a su lengua, esas expresiones se encuentran neutralizadas y entregan entonces un dato purificado de toda organización lingüística.

Teniendo en cuenta, por el contrario, que la estructuración lingüística contribuye a la vez a dar forma a la sustancia del sistema y a enmascarar su organización propia, vemos que la tarea del semiólogo es ardua. ¿Habrá de fiarse pues únicamente de su percepción de los hechos humanos? Sí, si fuera posible volver al carril de las psicologías fundadas únicamente en la introspección, de las lingüísticas cuyo único apoyo es el "sentido del lenguaje", homólogas a las físicas de la cualidad sensible. Sin duda alguna sería ilusorio y absurdo prohibir al sociólogo "comprender" los hechos sociales, al lingüista practicar la lengua que describe. Sin embargo, hay que reconocer que ninguna ciencia digna de ese nombre podría levantarse sobre ese punto de apoyo. Aquí es donde las técnicas lingüísticas pueden proporcionar mejor, quizá, paradigmas útiles. Conmutación y distribución son, como se sabe, los dos procesos ideales que los fonólogos presentan concurrentemente como criterios objetivos de segmentación. La primera consiste en recoger todas las ocurrencias variadas de la sustancia fónica en un medio fijo, no distinguiendo más que las ocurrencias que evocan diferencias de sentido en quienes usan la lengua. La segunda consiste en recoger todos los medios en los que aparece un segmento supuesto. Como se ve, estos dos procedimientos son duales en cierta forma, y no tenemos por qué discutir aquí sus méritos respectivos. 
En todo caso, permiten efectuar un censo reglamentado de lo que se considerará como segmentos fonológicos de una lengua, sin apelar a ningún contenido de lo significado, sino sólo a la noción formal mínima de diferencia de sentido. ${ }^{12}$

4.5. Pero cacaso no reposa el éxito de tal procedimiento justo en el carácter natural del sistema formal que constituye la articulación fundamental de una lengua? Para segmentar en unidades saussurianas los otros niveles de un sistema significante $\longrightarrow$ de una lengua - son necesarias las precauciones; y las dificultades aparecen también en la lingüística misma tan pronto como se quiere sobrepasar el nivel fonemático $y$, sobre todo, cuando se trata de alcanzar la organización semántica. Así, pues, no es necesario subrayar el carácter relativo $\mathrm{y}$, quizá, arbitrario, de la segmentación propuesta, recolocando en todos los casos el sistema en la red mucho más vaga y complicada de lo que llamamos las remisiones connotativas. En efecto, en esos sistemas simbólicos, el aislamiento de sistemas formales es infinitamente más mutilador de lo que es, en la lengua, la disociación de una fonología. Pues en ese último caso, el sistema formal así puesto ante la vista, si no tiene sin duda una realidad psicológica natural, tiene cuando menos una realidad funcional determinada, poco más o menos como la onda portadora de una señal de radio que, modulada en el mensaje efectivamente transmitido, no es percibida, sino que sigue presente de cierta manera. ¿Sucede lo mismo en los sistemas formales separados por el sociólogo, el antropólogo, el economista? En todo caso, la pluralidad esencial de tales sistemas hace que sus funciones respectivas sean excesivamente ambiguas. También nos está permitido considerar con cierta desconfianza las palabras "sememas", "mitemas", "gustemas" y cualquier otra del mismo jaez. No puede repetirse demasiado que los segmentos de diferentes sistemas formales extraídos de un sistema significante no pueden asimilarse de manera expeditiva a los fonemas de una lengua, ya que ninguno de estos sistemas ha desempeñado por sí solo el papel de estructura portadora fundamental de los sentidos; por el contrario, su pluralidad indeterminada es uno de los reflejos en la traducción objetiva del hecho, de la resistencia a la reducción de las significaciones.

4.6. Así, pues, las tareas preliminares de descripción "semántica" se reducen, con todas esas reservas, a la construcción de sistemas formales.

Podemos preguntarnos ahora de qué medios de expresión hay que disponer para este análisis y cuál podría ser el metalenguaje. Las matemáticas, sistema formal muy rico, proporcionan evidentemente, y proporcionarán, sin duda alguna, cada vez mejor los medios de producción de estructuras adecuadas a los diferentes niveles de reducción formal del hecho humano. Puestas en su lugar y surtidas del tipo de comentarios que hemos

12 Es evidente que siempre tomamos la palabra sentido en la acepción que formulamos en el $\S 3.2$. 
sugerido, una "estructura algebraica" de parentesco, una "estructura de juego" respecto a una situación económica, constituyen en opinión nuestra auténticos fragmentos de una ciencia del hombre. Pero no puede formularse matemáticamente la exposición de dichos comentarios. Al parecer las limitaciones del formalismo como metalenguaje, muy precisamente definidas en el seno de las matemáticas mismas por su enunciado goedeliano, se aplican a fortiori en la circunstancia y, más en particular, bajo la forma semántica que les dio Tarski. Así, pues, para ensamblar los sistemas locales legítimamente establecidos por el pensamiento formal, sólo se puede contar con los lenguajes naturales. De allí resulta evidentemente que las deducciones sacadas de esos multimodelos deben perder, en general, su rigor. Aquí no hay, como en matemáticas, un "principio de pegamento" de los diferentes espacios abstractos donde se figuran los rasgos ficticios del hecho humano que, entonces, aparece como sobredeterminado por cada una de sus imágenes. Ya en otra parte caracterizamos epistemológicamente la historicidad ${ }^{13}$ por esta sobredeterminación indefinida. Hay que decir pues que el control del saber lo efectúa aquí la historia, es decir, la aplicación del haz de modelos formales en los que se ha disociado un sistema significante, a la descripción de un acontecimiento tan circunstanciado como sea posible.

Pero hay que reconocer otro procedimiento de control de un análisis semiológico, procedimiento especialmente seductor, aunque, como ya hemos visto, necesariamente vicario. Consiste en formular, dentro de una perspectiva tomada en préstamo a los lingüistas, por medio de reglas de construcción, cada estructura formal hecha evidente y proporcionarse así el medio de producir artificialmente "mensajes", que se compararán con los hechos observados. Por ejemplo, una estructura algebraica de parentesco permite engendrar equivalencias aún no observadas entre relaciones complejas en un sistema dado, cuya validez podrá probarse por informadores competentes; o también, los principios generales de tal estructura podrán sugerir la construcción de estructuras particulares cuyas realizaciones concretas se buscará. Por desgracia, este género de verificación sólo es verdaderamente significativo en la medida en que el sistema formal así controlado sea funcionalmente lo bastante impregnante para que los "mensajes" simulados que permite engendrar no queden "revueltos" por completo por la interferencia de otros sistemas. Es verdad que esta dificultad no hace más que trasponer -agravándola - la que encuentra el constructor de modelos en las ciencias de la naturaleza, con los fenómenos que podrían calificarse en general de "frotamiento". Pero la dificultad específica y principal proviene de la elección de los jueces y de las modalidades de presentación de los simulacros.

13 "L'histoire comme analyse des oeuvres et comme analyse des situations", en Media. tions, $\mathrm{n}^{\circ}$ 1, 1961, pp. 127-2. 
En ciertos casos simples, este obstáculo es sin duda fácil de vencer: se trata, por ejemplo, de controlar las imitaciones de obras humanas, obtenidas por codificación parcial de su organización estilística. ${ }^{14}$ No sucede lo mismo con la imitación de situaciones humanas complejas. Pero puede sacarse sobre todo una lección de modestia, más que un pretexto para el descorazonamiento.

4.7. Así, la descripción analítica de los sistemas significantes, preliminar indispensable sin embargo a una explicación de los hechos humanos que ameriten el nombre de ciencia, se encuentra colocada en última instancia -repitámoslo - ante un dilema enorme. En efecto, necesitaría evitar a la vez dos especies de discurso insatisfactorias sobre su objeto. Por una parte, la construcción pura y simple de un modelo abstracto único, necesariamente plano, en el que largas cadenas deductivas podrían conducir a enunciados notables en sí mismos y lógicamente correctos, pero con mucha frecuencia incontrolables porque son imposibles de relacionarse a una observación concreta. Las teorias muy elaboradas de los economistas matemáticos proporcionarían un ejemplo de ello. ${ }^{15}$ Por otra parte, las descripciones-explicaciones de acontecimientos y de instituciones que se presentan como relatos, fieles al parecer a la complejidad de la vivencia, pero cuyos protagonistas siguen siendo abstracciones mal definidas y personificadas. Explicaciones cuyos principios generales son tan simples que escapan a cualquier verificación y cuyas hipótesis de detalle son introducidas ad hoc y retocadas a pedido. Para quien quiera disociar bien las doctrinas de acción y conocimiento científico, tales relatos interpretativos, inverificables e irrefutables, no pueden ocupar el lugar de un saber.

Así, pues, nuestra tesis es que el acontecimiento indisputado de las ciencias del hombre sólo tendrá lugar cuando se empiece a resolver el problema de establecer en términos conceptuales los sistemas significantes, sin sustituirlos por modelos formales únicos, ni por reconstituciones voluntaristas de la vivencia. Es evidente que el hecho humano no puede ser conocido científicamente más que a través de una pluralidad de geometrales, a condición, sin embargo, de que se descubra la operación controlable que lo restituya a partir de ellos estereoscópicamente.

14 Pensamos aquí en un ensayo inédito de J. Molino sobre el establecimiento de una "gramática generadora" de títulos de novelas policiacas de un autor popular en Francia, Jean Bruce. Es evidente que el éxito de la empresa está en relación con la extrema pobreza del sistema significante analizado. Pero el método es ejemplar.

15 Acerca de este punto puede leerse el análisis critico devastador de $O$. Morgenstern acerca de la poca validez de los descriptores estadísticos en política económica. También su artículo más reciente sobre las oscuridades, las fallas lógicas y las inadecuaciones notorias que puede denunciarse en las teorías más corrientes en política económica moderna ("Thirteen critical points in contemporary economic theory", en The Journal of Economic Literature, $\mathrm{X}, 4,1972$, p. 116). Sin embargo, como dijimos más arriba, seguimos creyendo en el valor heurístico de tales modelos, si se los reconoce como preliminares, impotentes por sí mismos. 
El logro de esta tarea es inseparable del reconocimiento de su carácter preliminar y parcial. En efecto, no se habrá perdido de vista que la descripción "semántica" de un sistema significante, sea cual fuere su interés propio, no se ha presentado aquí más que como condición necesaria para el establecimiento de modelos de funcionamiento, más específicamente de modelos cibernéticos (\$3.2. y 3.3.). Su fin es permitir la conceptualización de los contenidos y las formas de significación, y su representación en tales modelos como información que puede tratarse en abstracto. Dicho de otra manera, permite asignar en un sistema de relaciones abstractas lógica o matemáticamente manipulables un papel causal definido a las significaciones.

Del estudio de P. Bourdieu sobre el matrimonio y la representación de parentesco en la sociedad cabila ${ }^{16}$ podríamos tomar un ejemplo, entre otros, de ese buen uso del análisis saussuriano. El autor, partiendo de un conocimiento de las situaciones concretas, verifica la inadecuación "del lenguaje de la prescripción y de la regla" (p. 73), para relacionar el formalismo del sistema de parentesco con la práctica efectiva de los matrimonios. Se propone, pues, mostrar cómo los matrimonios son productos de hecho de estratagemas sociales, donde intervienen como motores "intereses" de diverso orden, y en las que la determinación genealógica dada por el sistema abstracto de parentèsco no sirve más que para delimitar parcialmente lo que el autor llama los "golpes permitidos". Vemos cómo la reducción del parentesco a su esquema algebraico se trata aquí como contenido posible de una de las especies de információn que circulan en un nudo de regulación del modelo, por el cual desempeñan los diversos "intereses" un papel energético.

4.8. Por seguros que puedan parecer, en relación con las ciencias garantizadas, los resultados obtenidos por este camino, nos parece que es aquí donde se revelan los primeros indicios de un conocimiento del hecho humano. Este pensamiento, formal, de los hechos humanos como objetos no podría dejar de serlo sin tender de inmediato a confundirse con una producción caricaturesca de relatos míticos. Y esta reducción formal se opera pues en dos registros que creemos radicalmente distintos, de la energética-cibernética y de la semántica. Pero esta última reducción, propia del terreno humano, conduce siempre a multiplicar los planos de lo formal, de manera que la inserción de esos resultados en las estructuras cibernéticas heredadas de las ciencias de la naturaleza destruye su univocidad.

He alli sin duda una de las razones principales y más generales por las

16 Esquisse d'une theorie de la pratique, Ginebra-París, 1972. Los dos primeros ensayos de la obra sobre el "sentido del honor" y sobre la "casa cabila" nos parecen menos ejemplares y más cercanos a la concepción aquí criticada, donde los sistemas significantes parecen demasiado "planos".

Sobre el ensayo teórico de la última parte, a pesar de proposiciones muy penetrantes, tendríamos personalmente algunas reservas, algunas de las cuales se deberían quizá a la ambigüedad literaria del estilo. 
que las ciencias del hombre desbarran, desarmadas, todavía hoy, ante la tarea de una traducción conceptual parcial, operatoria y, al mismo tiempo, intuitivamente aceptable, de las significaciones. Los recientes progresos de la lingüística han contribuido sobre todo a revelar la naturaleza y la extensión del problema; quizá las mejores cabezas los hayan interpretado demasiado pronto como lo que proporciona la solución universal, permitiendo que los retóricos produzcan, a placer, extravagantes imposturas sobre ese tema. El mal está seguro, el bien es todavía dudoso, como dice un teólogo amigo nuestro - muy pesimista, es verdad, por lo común - y que concluye: de allí la necesidad de la fe. Aquí no hay que hablar de fe, sino en todo caso de esperanza. Hubiéramos querido mostrar cómo y por qué no es irrazonable esperar.*

Princeton, marzo de 1973 .

Gilles G. Granger (Trad. de Elsa Cecilia Frost)

* Doy aqui las gracias al Institute for Advanced Study de Princeton, N. J., y al

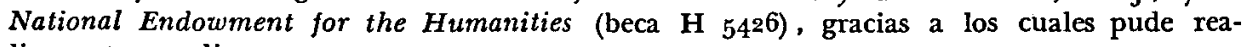
lizar este estudio. 